\title{
How Do Lawyers Assist Their Clients With Advance Care Planning? Findings From a Cross-Sectional Survey OF LAWyers in Alberta
}

\author{
Nola M. Ries, ${ }^{*}$ MaUreen Douglas, ${ }^{* *}$ \\ JESSICA SIMON, ${ }^{* * *}$ AND KONRAD FASSBENDER ${ }^{* * * *}$
}

\begin{abstract}
Advance care planning (ACP) is the process of thinking about, discussing and documenting one's preferences for future health care. ACP has important benefits: people who have a written directive are more likely to receive care that accords with their preferences, have fewer hospitalizations, and die in their preferred location. This article focuses on the important role that legal professionals have in advising and assisting clients with ACP. Studies report that people who have a written advance care plan are more likely to have received assistance in preparing the document from a lawyer than from a doctor. Yet virtually no research engages with the legal profession to understand lawyers' attitudes, beliefs, and practices in this important area. This article starts to fill this gap by reporting the findings of a survey of lawyers in the province of Alberta. The results reveal lawyers' practices in relation to $A C P$, their perceptions of their professional role and factors that support or hinder lawyers in working with clients on ACP, and their preferences for resources to assist them in helping their clients. To the authors' knowledge, this is the first survey of lawyers on their practices in relation to $A C P$.
\end{abstract}

\section{TABLE OF Contents}

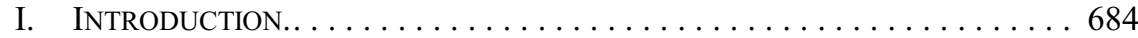

II. MEthods.. . . . . . . . . . . . . . . . . . . . . . . . . . . . . . . . . . . 686

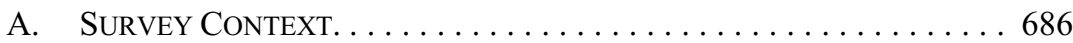

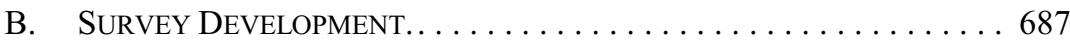

C. Statistical ANALYSis. . . . . . . . . . . . . . . . . . . . . 688

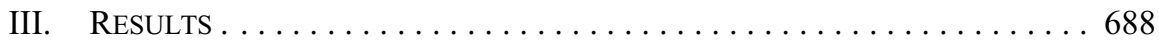

A. Factors That Motivate Client Engagement With ACP. . . . 688

B. TOPICS LAWYERS DisCUSS WiTH CLIENTS.. . . . . . . . . . . . . . . . 689

IV. BARRIERS TO ASSISTING Clients WiTh ACP. . . . . . . . . . . . . . . . 690

V. Professional Role Perceptions. . . . . . . . . . . . . . . . . . 691

A. LAWYERS' KNOWLEDGE OF SPECIFIC

HeAlth CARE System Documents ANd Processes. . . . . . . . . . . 692

* $\quad$ BA (Hons) JD, MPA, LLM, Associate Professor and Member of the Law|Health|Justice Research Centre, Faculty of Law, University of Technology Sydney, Australia and External Research Fellow, Health Law Institute, Faculty of Law, University of Alberta, Canada.

** BA, LLB, Senior Project Coordinator, Advance Care Planning Collaborative Research and Innovation Opportunities Program, University of Alberta.

*** MD, FRCPC, Associate Professor and Division Head for Palliative Medicine in the Faculty of Medicine, University of Calgary, and Physician Consultant, Advance Care Planning and Goals of Care, Calgary Zone, Alberta Health Services.

**** PhD, Assistant Professor and Scientific Director, Covenant Health Palliative Institute, Faculty of Medicine and Dentistry, University of Alberta. We acknowledge funding support from the Alberta Innovates Health Solutions Collaborative Research and Innovation Opportunities (CRIO) Program Grant \#201201157 as well as Campus Alberta funding. We thank members of the Canadian Bar Association and other stakeholders who contributed their time and expertise to the survey development. Patricia Biondo, Research Manager, Advance Care Planning CRIO Program, provided tireless organizational support for this research project. 


\section{B. RESOURCES LAWYERS CURRENTLY USE}

AND WHAT THEY WOULD FIND HELPFUL. . . . . . . . . . . . . . . . 693

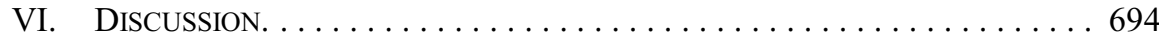

A. Comparing Health and Legal Professionals. . . . . . . . . . . 694

B. Professional Siloes. . . . . . . . . . . . . . . . . . . . 695

C. THE NEED FOR RESOURCES. . . . . . . . . . . . . . . . . . . . . . . . 696

VII. STRENGTHS, LIMITATIONS, AND IMPLICATIONS

FOR RESEARCH AND PRACTICE. . . . . . . . . . . . . . . . . . . . . . 696

VIII. CONCLUSION. . . . . . . . . . . . . . . . . . . . . . . . . . . . . . 698

APPENDIX A: DETAILED SURVEY RESUlTS.. . . . . . . . . . . . . . . . . . . 699

\section{INTRODUCTION}

Advance care planning (ACP) is a process of thinking about, discussing and documenting one's preferences for future health care. Specific legal rules and processes vary across countries, but in general, ACP is supported by laws that recognize the right of adults with decision-making capacity to express their wishes for future health and personal matters, with the expectation they will be followed. These rights are underpinned by common values and aims. The right to plan for what happens to oneself during future periods of incapacity promotes self-determination, respects individual autonomy, and enables person-centered care. A person may document specific wishes and personal values in a written advance care directive and designate decision-makers who will have legal authority to make choices on their behalf during periods of incapacity. People who have a written directive are more likely to receive care that accords with their preferences, have fewer hospitalizations, and die in their preferred location. ${ }^{1}$ Substitute decision-makers report reduced decisional conflict when their choices are guided by prior ACP conversations. ${ }^{2}$ Effective ACP may also have economic benefits by reducing health care costs. ${ }^{3}$

Much research has focused on the barriers and enablers to ACP for health care providers and patients. Complex factors at personal, organizational, and system levels influence ACP behaviours. ${ }^{4}$ Interventions to promote ACP occur mainly in health care settings using diverse strategies that include educational programs for care providers and clients, ACP worksheets and forms, and deployment of trained ACP facilitators. ${ }^{5}$ Researchers have called for better-

Arianne Brinkman-Stoppelenburg, Judith AC Rietjens \& Agnes van der Heide, "The Effects of Advance Care Planning on End-of-Life Care: A Systematic Review" (2014) 28:8 Palliative Medicine 1000 at 1000; Carmen HM Houben et al, "Efficacy of Advance Care Planning: A Systematic Review and MetaAnalysis" (2014) 15:7 J American Medical Directors Assoc 477 at 484; Hilary D Lum, Rebecca L Sudore \& David B Bekelman, “Advance Care Planning in the Elderly" (2015) 99:2 Medical Clinics North America 391 at 393.

2 Jared Chiarchiaro et al, "Prior Advance Care Planning is Associated With Less Decisional Conflict Among Surrogates for Critically Ill Patients" (2015) 12:10 Annals American Thoracic Society 1528 at 1533.

3 Rory O’Sullivan et al, “Advance Directives: Survey of Primary Care Patients” (2015) 61:4 Can Family Physician 353.

$4 \quad$ Aline De Vleminck et al, "Barriers and Facilitators for General Practitioners to Engage in Advance Care Planning: A Systematic Review" (2013) 31:4 Scandinavian J Primary Health Care 215; NA Hagen et al, "Advance Care Planning: Identifying System-Specific Barriers and Facilitators" (2015) 22:4 Current Oncology 237; Susi Lund, Alison Richardson \& Carl May, "Barriers to Advance Care Planning at the End of Life: An Explanatory Systematic Review of Implementation Studies" (2015) 10:2 PLoS One 1. Ruth S Martin et al, "The Effects of Advance Care Planning Interventions on Nursing Home Residents: A Systematic Review” (2016) 17:4 J American Medical Directors Assoc 284 at 288-90. 
designed studies and the development of rigorous evaluation frameworks to build the evidence base on what works to improve the uptake and use of ACP. ${ }^{6}$

Discussion and documentation of clients' wishes is vital in health care settings, but it is equally important to improve engagement with ACP in other contexts. In its landmark report, Dying in America, the Institute of Medicine championed a "whole-community" approach to the promotion of ACP. ${ }^{7}$ Ideally, people should engage with ACP before crisis situations arise, in consultation with family, friends, and relevant professional advisors, while they have the capacity to make and communicate their decisions.

This article focuses on the important role that legal professionals have in advising and assisting clients with ACP. Our work is motivated by previous studies reporting that people who have a written advance care plan are more likely to have received assistance in preparing the document from a lawyer than from a doctor. In Canada, a survey of residents of the province of Saskatchewan found that almost half of the respondents who had a written care plan had sought help from a lawyer to prepare the document, while only 5 percent had consulted with a doctor. ${ }^{8}$ In Ontario, patients of a family practice clinic were more likely to have discussed ACP with a lawyer than their family doctor. ${ }^{9}$ A national study of sick, elderly patients and their family members found that participants discussed their end-of-life care wishes as often or more often with a lawyer than with a family doctor or medical specialist. ${ }^{10}$

In the United States, a survey of adults admitted to four hospitals in California found that of those with advance directives at the time of admission, 49 percent had received help from a lawyer to prepare ACP documents and only 6 percent had received help from a doctor. ${ }^{11}$ Thirty-five percent of those with directives viewed lawyers as helpful sources of expertise in assisting with writing the documents and only 1 percent said physicians were. An earlier study in Connecticut found that, among people admitted to a hospital with an advance directive, 76 percent had prepared the document with a lawyer and only 7 percent had been prepared with a doctor. ${ }^{12}$ In Germany, Matthias Becker and co-authors surveyed 53 people who had an advance directive to find out if they had obtained help from a professional in preparing the document. Just under a quarter of people had sought such help and, among those, legal professionals were the most common source of advice. ${ }^{13}$

Lawyers are a key source of help for people who want to do ACP, yet virtually no research engages with the legal profession to understand lawyers' attitudes, beliefs, and

Ibid at 284. See also Patricia D Biondo et al, "How Healthcare Systems Evaluate Their Advance Care Planning Initiatives: Results From a Systematic Review” (2016) 30:8 Palliative Medicine 720 at 721. Institute of Medicine, Dying in America: Improving Quality and Honoring Individual Preferences Near the End of Life (Washington, DC: National Academies Press, 2014) at 3-6.

D Goodridge et al, "Planning for Serious Illness by the General Public: A Population-Based Survey" [2013] ISRN Family Medicine 483673, online: <https://www.ncbi.nlm.nih.gov/pmc/articles/PMC 4041261/>.

Daren K Heyland et al, "Failure to Engage Hospitalized Elderly Patients and Their Families in Advance Care Planning" (2013) 173:9 JAMA Internal Medicine 778.

Marc Tunzi, "Advance Care Directives: Realities and Challenges in Central California" (2011) 22:3 J Clinical Ethics 239.

Natalya Thorevska et al, "Patients' Understanding of Advance Directives and Cardiopulmonary Resuscitation" (2005) 20:1 J Critical Care 26.

Matthias Becker et al, "Did You Seek Assistance for Writing Your Advance Directive? A Qualitative Study” (2010) 122:21 \& 22 Wiener Klinische Wochenschrift 620. 
practices in this important area. This article aims to start filling that gap. Gaining an understanding of what lawyers currently do in practice, especially their perspectives on the barriers and enablers to ACP and the resources that would help them better serve their clients, is a vital first step in devising interventions to improve lawyers' practices and enhance interprofessional collaboration between lawyers and health care professionals.

This article reports on a survey of lawyers in the province of Alberta. The objective of this study was to find out about lawyers' practices in relation to ACP, their perceptions of their professional role and the factors that support or hinder lawyers in working with clients on $\mathrm{ACP}$, as well as their preferred resources for assisting their clients.

\section{MethodS}

A cross-sectional survey of lawyers practicing in Alberta was undertaken in 2016. The online, anonymous survey was promoted over a four-month period (late February to late June) to practicing lawyers via email, in addition to websites, e-newsletters and social media from the Canadian Bar Association, the Law Society of Alberta and the Legal Education Society of Alberta. Due to anti-spam legislation, the legal professional organizations that disseminated the survey were unable to email the survey invitation directly to lawyers who self-identify as practicing in our target areas of wills and estates, elder law, and health law. A screening question at the start of the survey asked respondents whether, in their current professional role, they assist clients with planning for future mental incapacity by writing a personal directive, enduring power of attorney, appointing an agent, or other matters related to ACP. Lawyers who responded "no" were discontinued from completing the survey.

\section{A. Survey ConteXt}

With a population of nearly 4.2 million people, Alberta is Canada's fourth most populous province and around 12 percent of residents are aged 65 and over. ${ }^{14}$ The government health department, Alberta Health Services, promotes ACP through its Conversations Matter initiative. ${ }^{15}$ The Alberta Personal Directives $A c t^{16}$ gives adults with decision-making capacity the right to document their wishes for future health care and to appoint a person (an agent) with legal authority to make health care decisions during the appointer's future periods of incapacity. The government provides a personal directive form as a guide, ${ }^{17}$ however, a person making a directive can use another document for this purpose provided it is signed and witnessed as required by the statute. A person may file their directive with a voluntary government registry. ${ }^{18}$ The Alberta Powers of Attorney Act ${ }^{19}$ enables a person to appoint a

Statistics Canada, "Chart 4: Proportion of the Population Aged 0 to 14 Years and 65 Years and Older, July 1, 2015, Canada, Provinces and Territories," online: <www.statcan.gc.ca/daily-quotidien/150 929/cg-b004-eng.htm>.

15 Alberta Health Services, "Conversations Matter - Advance Care Planning Goals of Care Designation: A Guide for Making Health Care Decisions," online: < goals.conversationsmatter.ca>. RSA 2000, c P-6.

Alberta Human Services, "Write a Personal Directive," online: <www.humanservices.alberta.ca/ guardianship-trusteeship/write-a-personal-directive.html>.

Alberta Human Services, "Register a Personal Directive," online: <www.humanservices.alberta.ca/ guardianship-trusteeship/register-a-personal-directive.html>.

RSA 2000, c P-20. 
person, known as an enduring power of attorney, to make decisions about financial matters or property if the appointer loses capacity.

\section{B. SURVEY DEVELOPMENT}

The survey instrument was developed through a multi-disciplinary consultative process involving members of the legal profession in Alberta. We used Susan Michie and co-authors' Theoretical Domains Framework to inform the survey development, ${ }^{20}$ taking account of the 14 domains that influence behaviour change and the uptake of new practices. ${ }^{21}$ As the survey focused on individual practitioner behaviours, we explored seven domains: knowledge, skills, professional/social role and identity, beliefs about capabilities, emotion, beliefs about consequences, and social influences. Dialogue between members of our research team and the legal profession began in 2014 with a series of meetings involving a total of around 100 lawyers who are members of the Canadian Bar Association (CBA), ${ }^{22}$ a professional association for lawyers. The lawyers participated in interest groups for three practice areas relevant to ACP: wills, estates and trusts, elder law, and health law. The meetings were an opportunity to introduce our multidisciplinary research team to members of the legal profession, especially to those in CBA leadership positions. Topics discussed included the types of issues clients raise with lawyers in relation to ACP, legislation governing advance personal planning, and lawyers' perceptions of barriers and facilitators to engaging their clients with ACP.

In 2015, the research team convened two focus groups of 12 to 15 lawyers and other stakeholders, including chairs of the CBA interest groups, lawyers in private practice with significant ACP experience, lawyers working in the legal aid and government health sector, and representatives from the Legal Education Society, the Office of the Public Guardian and Trustee (the provincial government office that promotes advance personal planning and deals with guardianship matters for people with cognitive disabilities), ${ }^{23}$ palliative care physicians, ethicists, social workers, and patient advisors. We discussed the draft survey and pre-tested it with eight lawyers, two government health policy experts, and a patient advisor.

The survey consisted of 15 questions that were primarily close-ended items with Likert category responses. ${ }^{24}$ For many questions, respondents could select "other" as a response with an option to provide an open-ended answer in a text box. The first section of the survey asked lawyers about their experiences and current practices in assisting their clients with $\mathrm{ACP}$, including the topics they cover in ACP conversations and the resources they use. Several questions explored their beliefs about their professional role in relation to ACP, as well as their views on the perceived benefits of ACP and the barriers to assisting their clients. The middle section of the survey asked lawyers about their preferences for the types of ACP

S Michie et al, "Making Psychological Theory Useful for Implementing Evidence Based Practice: A Consensus Approach" (2005) 14:1 Quality \& Safety in Health Care 26 at 29-30.

See also Hagen et al, supra note 4.

The Canadian Bar Association, online: $<$ https://www.cba.org/>.

Ontario Ministry of the Attorney General, "The Office of the Public Guardian and Trustee (OPGT)," online: <https://www.attorneygeneral.jus.gov.on.ca/english/family/pgt/>.

Likert scales in surveys ask respondents to indicate their level of agreement with statements, for example, on a scale from strongly agree to strongly disagree. For discussion see e.g. Gail M Sullivan \& Anthony R Artino Jr, "Analyzing and Interpreting Data From Likert-Type Scales" (2013) 5:4 J Graduate Medical Education 541. 
resources they would find useful, as well as their preferred format for accessing resources. The final section of the survey collected demographic information.

\section{Statistical Analysis}

We performed descriptive analyses to describe the frequency of responses in each Likert category and to rank responses by frequency of facilitators and barriers to engaging clients in ACP. The full results are available in Appendix A. For ease of interpretation, we present collapsed results in three categories: Never or Seldom; Sometimes; Often or Always.

\section{RESULTS}

The total number of survey respondents was 133, with 104 surveys completed in full. We estimate a 7.7 percent response rate based on the 1,840 lawyers in the province who are listed in Law Society records as practicing in wills and estates, the practice group targeted by the newsletters and social media activity that promoted the survey. The Law Society of Alberta advised us that it typically expects a response rate of 3 to 4 percent when it conducts surveys of lawyers; as a result, we did not aim for our study to produce results that would represent the practices of lawyers across the province or produce statistically significant associations between respondents' characteristics and their reported beliefs and experiences. Instead, the responses of the lawyers who completed the survey provide valuable and novel insights into the views of an experienced and knowledgeable population of practitioners. Over threequarters of respondents (77 percent) reported ten or more years of experience in legal practice, 17 percent had between two and ten years of experience and 6 percent had been in practice for less than two years. Two thirds of respondents ( 66 percent) are sole practitioners or work in small firms of two to nine lawyers, and 20 percent work in mid-size or large firms (between 10-49 lawyers and 50 or more lawyers, respectively). A majority of respondents (69 percent) reported they assist clients with ACP on a daily or weekly basis. The remainder (31 percent) said they advise clients on a monthly basis. The fact that most respondents have significant experience and regularly engage in ACP provides greater confidence in using the survey results as an informative starting point for further work with the legal profession, including the development of resources to respond to knowledge and practice gaps revealed by this study.

\section{A. Factors That Motivate Client Engagement With ACP}

Respondents were asked what factors motivate a client to engage in ACP (see Figure 1). Ninety percent of lawyers said they often or always bring up the topic as part of a broader discussion of advance personal planning, such as writing a will and appointing a decisionmaker to manage financial matters during any future periods of incapacity. Declining personal health and experiencing the illness or death of someone close them are strong motivators for clients to engage in ACP. Nearly three-quarters of the respondents (73 percent) said that clients were motivated to engage in ACP after receiving a medical diagnosis with life-limiting implications or due to deteriorating health. Even more lawyers reported that clients wanted to do ACP because they had experience as a caregiver or substitute decision-maker for another person ( 80 percent) or someone close to them had been ill or died (88 percent). Interestingly, lawyers reported it was more common for a client to engage in ACP following a discussion with a financial sector advisor ( 70 percent reported 
this was is sometimes or often the motivator) than with a doctor or other health care provider (54 percent said this is sometimes or often a motivator). Several respondents volunteered that other factors prompting their clients included discussions with family or friends about ACP or media reports about end-of-life issues.

Figure 1:

Factors That Prompt a Client to Engage in ACP

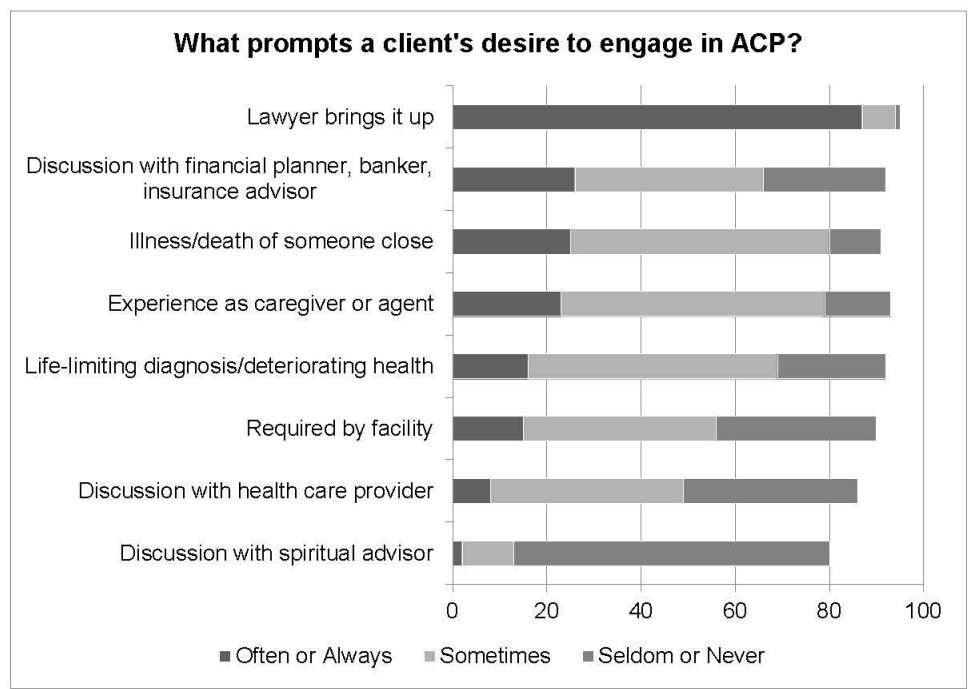

\section{B. TOPICS LAWYERS DisCUSS With CLIENTS}

Lawyers were asked about the topics they discuss with clients during consultations about ACP (see Figure 2). Eighty to 90 percent of respondents say they always or often discuss: the appointment of a suitable person to act as a substitute decision-maker should the client experience future periods of impaired capacity; the client's views on other people who should be involved in consultations with health care providers if the client loses capacity to make their own decisions; and the client's values and wishes concerning future care. Threequarters of respondents said they often or always discuss with the client whether they would want specific medical interventions (e.g. CPR, tube feeding) and around 60 percent said they always or often ask the client about their preferences for living arrangements or accommodation in the future, as well as their views on organ donation and who should have access to their health records. Just over 40 percent of respondents said they always or often ask their clients about their wish to participate in medical research. We did not define "medical research" in the survey, however, we suspect that lawyers understood this question to refer to discussions about the client's interest in donating their body for post-mortem research, not the client's wishes about inclusion in research during future periods of incapacity. ${ }^{25}$

25 Several researchers in Canada are investigating strategies to increase the uptake of advance directives both for health care and research participation. See Gina Bravo et al, "Promoting Advance Planning for Health Care and Research Among Older Adults: A Randomized Controlled Trial" (2012) 13:1 BMC Medical Ethics, online: <https://www.biomedcentral.com/1472-6939/13/1>. 
FiguRE 2:

Topics Lawyers and Clients Discuss as Part of ACP

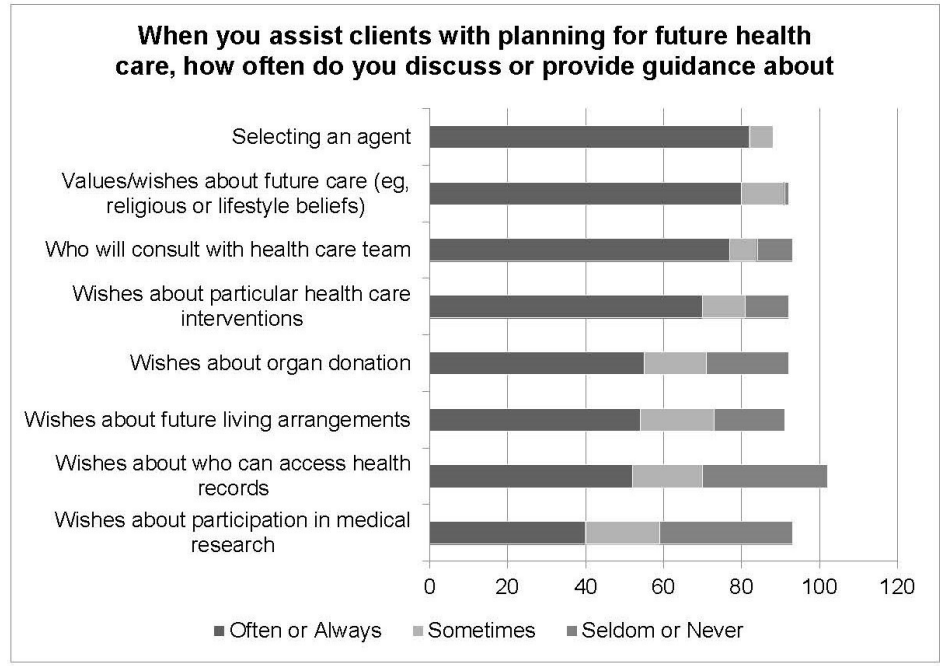

As communication of one's wishes with key people is an important component of ACP, lawyers were asked who they encourage their clients to speak to about their wishes for future health care. Nearly all respondents (99 percent) said they always or often encourage clients to speak to the person they appoint as their designated health decision-maker and nearly 80 percent said they always or often encourage conversations with family members, care givers, or friends other than the named decision-maker. Surprisingly, the results were less uniform with regard to encouraging clients to talk to their doctor or health care provider about their wishes. Just over 20 percent of respondents said they never or seldom encourage this, around 35 percent said they sometimes do, and less than half (44 percent) said they often or always do so.

In general, spiritual advisors are not reported as key people. Nearly 70 percent of the lawyers we surveyed never or seldom encourage their clients to talk to spiritual advisors about their wishes for health care, and three-quarters of respondents said that conversations with spiritual advisors are never or seldom a factor that prompts their clients to engage in ACP.

\section{BARriers to Assisting Clients With ACP}

Lawyers were asked about barriers they feel impede them in assisting their clients with ACP (see Figure 3). The options presented to them covered both practitioner and clientcentered barriers. The most significant client-centered barrier was the clients' lack of preparedness to engage in ACP; nearly three-quarters (73 percent) of respondents said this is sometimes or often a problem. A client's unwillingness to share personal details with a lawyer was identified as a hindrance to ACP for slightly under half (44 percent) of lawyers, and 55 percent said such reticence is seldom or never a problem. 
For a majority of lawyers, the potentially emotional nature of discussing future medical treatment and end-of-life care preferences with clients was not a barrier to ACP discussions. Almost 95 percent of lawyers said they never or seldom find ACP discussions upsetting or uncomfortable and 82 percent said concerns with upsetting the client were never or seldom an issue. Similarly, for most respondents ( 86 percent), age, cultural, or religious differences between the lawyer and client are seldom or never a barrier. Only around 20 percent of lawyers cited the additional time needed for ACP conversations - and thus higher costs for clients - as a barrier.

Just under half of lawyers revealed some degree of concern with their own lack of knowledge about the medical aspects of ACP and health sector policies and practices. A strong majority of respondents expressed confidence in their knowledge of the law relevant to ACP, a finding consistent with the level of experience of the respondent population.

In general, respondents had positive attitudes toward ACP and confidence in the value for their clients of documenting their wishes for future health care. Around three-quarters of respondents stated they believe ACP significantly benefits their clients and that advance care plans will be used in practice.

Figure 3:

Barriers to Engaging Clients With ACP

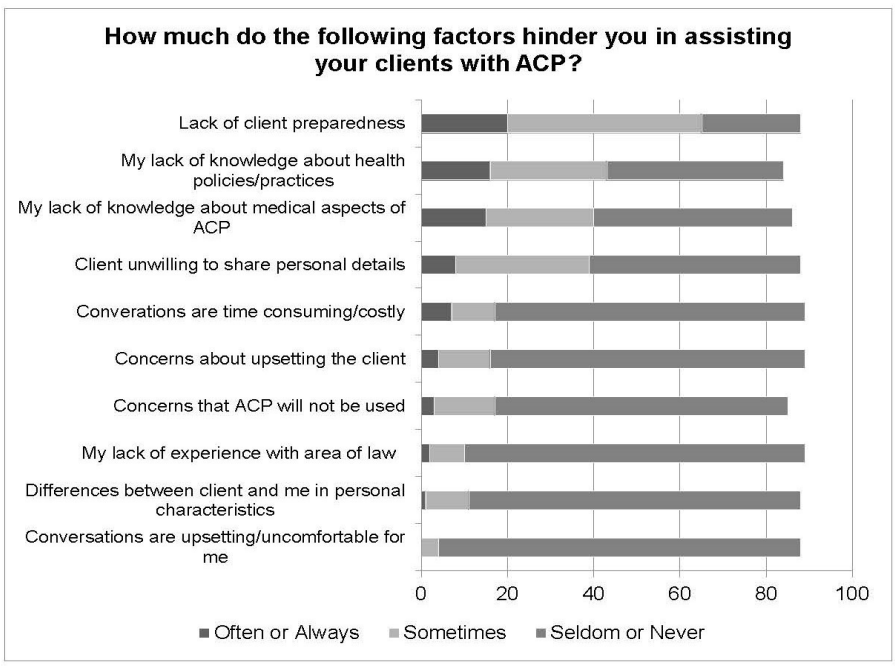

\section{Professional Role Perceptions}

Given that ACP is often promoted in health care settings, we sought to determine lawyers' views on the extent to which various ACP-related activities were perceived as part of a lawyer's professional role (see Figure 4). Respondents had consistent views about the activities they viewed as a significant part of a lawyer's role, including initiating ACP conversations, providing ACP information, drafting specific legal documents, advising on how to minimize future disputes, and encouraging clients to discuss their wishes with key 
others. In contrast, most respondents said that liaising with a client's health care provider (with the client's consent) was not at all, or only minimally part of their role.

Figure 4:

Lawyers' Role Perceptions About ACP Activities

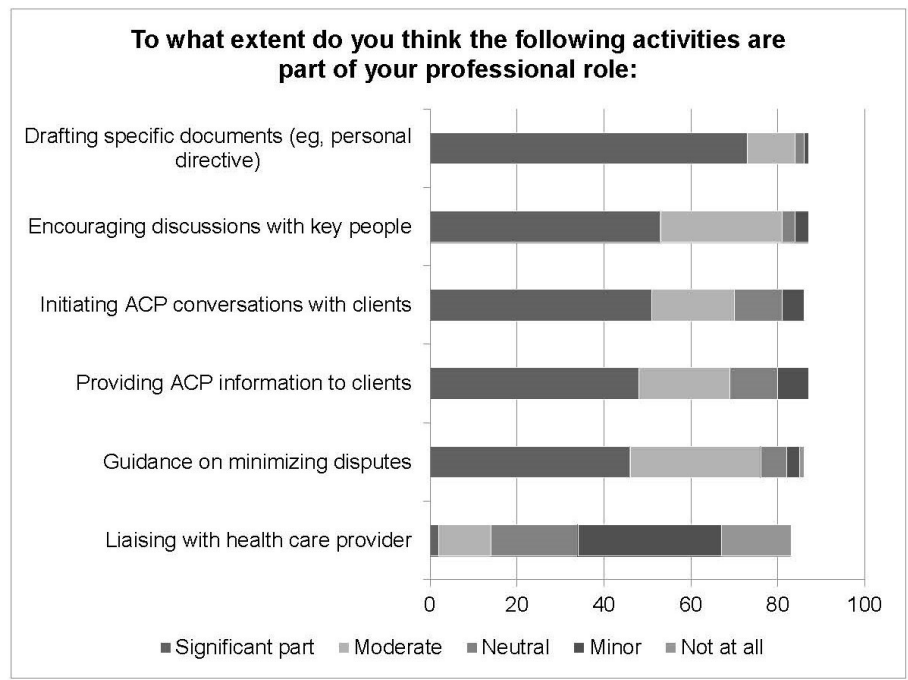

\section{A. LaWyers' KnOWledge of Specific Health Care SYSTEM DOCUMENTS AND PROCESSES}

The survey asked about lawyers' knowledge of two key provincial health system initiatives aimed at improving communication about and compliance with people's health care wishes, especially for end-of-life care. These are the Goals of Care Designation (GCD) and Green Sleeve. ${ }^{26}$ A GCD is a medical order that communicates the general intent of care (resuscitative, medical, or comfort care) and provides direction on specific interventions and locations of care. A doctor or nurse practitioner prepares the order in consultation with the patient (or a legally authorized decision maker if the patient lacks decision-making capacity). The Green Sleeve is a green plastic folder used to store ACP documents, including a conversation tracking record, advance directive, and GCD order. Patients can obtain a Green Sleeve from their health care provider and are directed to keep their care planning documents in the folder and to bring it to all appointments. Health care providers are trained to ask patients for their Green Sleeve and to check whether documents in the folder accurately reflect their current wishes. Patients are also educated to keep the Green Sleeve on or near their refrigerator at home as emergency medical responders are trained to look for it in that location. online: $<$ https://myhealth.alberta.ca/Alberta/Pages/advance-care-planning-conversation-matters.aspx $>$. 
Since lawyers are important advisors for clients on ACP, ideally they should be aware of government and health sector initiatives and be able to educate their clients using messages that are consistent with what they hear in health care settings. Approximately half of respondents ( 51 percent) said they knew what a GCD is, and 46 percent were familiar with a Green Sleeve. Just over one third of lawyers reported that their clients have discussed or shared their Green Sleeve and associated documents during a legal appointment.

\section{B. RESOURCES LAWYERS CURRENTLY USE AND WHAT THEY WOULD FIND HELPFUL}

A majority of the respondents (97 percent) use an advance directive template. Legislation in Alberta does not mandate the use of a specific statutory form and lawyers reported varying sources for the template they use. Lawyers commonly said that they used a law firm precedent or a template they had personally developed. Only one lawyer reporting getting health care provider feedback on the template they developed. Several respondents volunteered that they review and modify templates periodically (for example, every two years) to take account of new legal or policy developments. In contrast, one lawyer stated that the firm rarely modifies its template, with specific religious requests of a client being one basis for modifying the standard form. Lawyers who mentioned an external source for a directive template commonly mentioned the Legal Education Society of Alberta, an organization that provides continuing professional education and development for lawyers in the province. ${ }^{27}$

Respondents were asked about the usefulness of eight different ACP resources. The vast majority of respondents rated all but one of the resources as "useful" or "very useful": information about how GCD orders and Personal Directives function together in practice (89 percent of respondents said "useful" or "very useful"); a best practice guide for ACP (83 percent); information about health care service policies and resources (83 percent); worksheets for clients to identify and express their values, wishes and preferences (81 percent); legal resources (78 percent); and an explanation of relevant health care issues, language or specific disease and treatment (78 percent). Just over half of respondents (52 percent) said that a third party with specialized training in ACP would be useful or very useful.

Nearly three-quarters (74 percent) of respondents said they would prefer an online format for these ACP resources. When asked about their preferred format for continuing professional development, the majority (64 percent) said they prefer in-person seminars. Printed and webinar formats were preferred by 47 percent and 34 percent of respondents, respectively. 


\section{DISCUSSION}

\section{A. Comparing Health and Legal Professionals}

Various studies have investigated health care providers' perceptions of barriers that hinder them in engaging patients in ACP. In a 2015 systematic review, Susi Lund and co-authors reported that key barriers were competing work demands, the potentially emotional and timeconsuming nature of ACP conversations, and beliefs that care plans will not be followed even if they are made. ${ }^{28}$ It has been urged that health care providers must overcome the taboos of talking about future incapacity and the end-of-life in order to engage their clients in ACP; practitioners who avoid these conversations miss "a golden opportunity to let the person open up to what is important in their lives and what is worrying them." ${ }^{29}$ ACP must be normalized into medical care; just as doctors counsel on disease screening and healthy lifestyles, they ought to raise ACP if they are to achieve person-centered care that includes the values and preferences of patients in medical decision making.

Our survey results show that lawyers who regularly see clients about matters related to advance planning, such as making a will, believe that discussing ACP is a significant part of their professional role and that they routinely raise the topic with their clients. Concerns about the emotional aspects of ACP conversations were not identified as barriers. This may reflect differences in the physical and psychological environment of a law office compared to a medical setting. When a care provider raises ACP in hospital, the immediacy and gravity of incapacity and end-of-life choices may have a more potent emotional impact for the practitioner and the patient. However, as Ebony Lewis and co-authors suggest, "the timing of broaching the subject of ACP does not have to be at the vulnerable moment of irreversible crisis. It is more productive to discuss [advance care directives] before the terminal stages, during routine examinations before drastic decisions are required. ${ }^{\prime 30}$

Another possible difference between legal and health care professionals is that lawyers may see ACP as an empowering act for clients and an important way for clients to protect their interests, both in terms of what happens to their property and what happens to their body. In contrast, health care professionals may worry that ACP distresses clients and takes away their hope, despite evidence that a majority of elderly and frail people want to discuss end-of-life care. ${ }^{31}$ The relationship between a lawyer and client is a highly confidential one and, as in the doctor and patient relationship, the promise and expectation of confidentiality are important to encouraging open communication. Client reluctance to share personal details with lawyers was not reported as a frequent barrier to ACP discussions. Lawyers are also trained to elicit and take instructions from their clients and the nature of this professional obligation means lawyers must raise potentially sensitive topics to determine what the client wants, then express these instructions in legal documents. In health care settings, there is

28 Lund, Richardson \& May, supra note 4 at 11.

29 Joel J Rhee, Nicholas A Zwar \& Lynn A Kemp, "Uptake and Implementation of Advance Care Planning in Australia: Findings of Key Informant Interviews” (2012) 36:1 Australian Health Rev 98 at 100. Ebony Lewis et al, "Evidence Still Insufficient That Advance Care Documentation Leads to Engagement of Healthcare Professionals in End-of-Life Discussions: A Systematic Review" (2016) 30:9 Palliative Medicine 807 at 816.

$31 \quad$ Tim Sharp et al, "Do the Elderly Have a Voice? Advance Care Planning Discussions With Frail and Older Individuals: A Systematic Literature Review and Narrative Synthesis” (2013) 63:615 British J General Practice 657 at 659 . 
evidence of persistent deference to medical authority where patients and family members rely on a doctor's advice of the best course of action. ${ }^{32}$

There has been criticism that lawyers are too transactional in their approach to advance planning and focus merely on the preparation of documents. ${ }^{33}$ Our results show that lawyers do encourage conversations between their clients and key people who need to know the person's wishes, including their appointed decision maker, family members, and friends. Our respondents had confidence in the value of ACP for their clients and some of the lawyers we consulted in focus groups to develop the survey were alarmed by anecdotal accounts that advance directives were not always followed in practice. Lawyers were also concerned to learn that statements in advance directives are not always relevant to subsequent medical situations. This may reflect lawyers' distance from the practical reality of healthcare delivery and the complexity of decision-making when a client becomes seriously ill and end-of-life care choices need to be made.

\section{B. Professional Siloes}

Our survey results exposed the siloed nature of legal and health care practice. Surprisingly, it is not standard practice for lawyers to encourage their clients to discuss their health care wishes with their doctor. Lawyers also do not see liaising with health care providers as part of their professional role. While the time and cost of advising clients about planning for future incapacity was not a barrier to ACP discussions, these factors may be an impediment to greater collaboration between legal and health professionals. A lawyer who spends time making contact with a client's health care provider will typically charge a client more for that service, and public funding for health services in Canada does not include reimbursement for this type of medical-legal collaboration. The siloes between legal and medical expertise may contribute to some of the known deficiencies with ACP. For example, directives may be held by lawyers and the client, but not produced to health care providers when needed.

We have argued elsewhere for a framework for action on health-legal collaboration to support ACP. ${ }^{34} \mathrm{We}$ call for legal and health practitioners to use common best practices to assist their clients, cooperate in interprofessional training and, where feasible, offer joint ACP clinics to clients and even move to integrating legal professionals into health care teams. An important first step is to meet lawyers' needs for resources that can help them more effectively assist their clients with planning for future health care.

33 Lesley S Castillo et al, "Lost in Translation: The Unintended Consequences of Advance Directive Law on Clinical Care" (2011) 154:2 Annals Internal Medicine 121 at 122.

34 Nola M Ries et al, "Doctors, Lawyers and Advance Care Planning: Time for Innovation to Work Together to Meet Client Needs" (2016) 12:2 Healthcare Policy 12 at 13. 


\section{THE NEED FOR RESOURCES}

Our respondents reported a strong interest in resources to assist them with ACP consultations. Clients' lack of preparedness is a commonly cited barrier by lawyers and health care providers alike and resources like worksheets can help clients think about and articulate their wishes. This could improve the comprehensiveness of the instructions that clients give to their lawyers and could enhance the quality of documents that lawyers draft for their clients. Resources to increase lawyers' knowledge of health system policies and procedures, as well as basic educational materials on medical terminology and treatments, would also help bridge the divide between the legal and health care domains. Strategies developed to promote ACP and the sharing of documents (Alberta's Green Sleeve initiative, for example $)^{35}$ should be communicated to lawyers as they are important advisors for clients on organizing their affairs and planning for future incapacity and death. Organizations that develop and disseminate ACP resources should liaise with legal professional associations about lawyers' needs, and those associations can themselves provide further continuing professional education on ACP.

\section{STRENGTHS, LiMitations, AND IMPLICATIONS FOR RESEARCH AND PRACTICE}

To our knowledge, this is the first survey of lawyers regarding their practice in relation to ACP. Our respondents represent experienced professionals who regularly assist clients with ACP. The response rate was low, but higher than what the Law Society suggested we could expect. Our survey was promoted during a period when lawyers also received numerous communications from the Law Society about volunteering to support residents and lawyers evacuated from a city that was severely affected by a wildfire that swept the area and destroyed over 2,000 homes and buildings. ${ }^{36}$ The urgency of this appeal may have overshadowed our survey.

The findings reflect the practices and attitudes of lawyers in one Canadian province, but having worked extensively with the legal profession and other stakeholders in the survey development, we hope to use it to collect data in at least three other Canadian provinces.

Previous studies note that barriers and enablers to ACP exist in three domains: client/patient; professional/provider; and system-level. Our survey focused on the lawyer and client domains, and future research could explore system-level factors that influence legal practice, as well as barriers and enablers to collaboration among health care and legal professions to provide more integrated supports for ACP.

There is also a need for more in-depth research about lawyers' practices. For example, a majority of our survey respondents said they use a template for ACD. The source, content, and user experiences with such templates - both lawyers and clients — are areas for further

See Government of Alberta, supra note 26.

For the legal profession responding to calls for support for wildfire victims, see David Dias, "Alberta Law Firms Offer Generous Support to Wildfire Victims," Canadian Lawyer (12 May 2016), online: $<$ www.canadianlawyermag.com/legalfeeds/alberta-law-firms-offer-generous-support-to-wildfirevictims-6898/>. 
investigation. Studies elsewhere have shown that the quality of such templates may be a concern. In Germany, Matthias Becker and co-authors found that lawyers who downloaded templates from the Internet rarely modified them to deal with their clients' particular circumstances. ${ }^{37}$ It has been observed that directives in legalistic and complicated language are unlikely to influence treatment decisions. ${ }^{38}$

It is important to investigate whether the documents that lawyers prepare accurately reflect their clients' wishes and whether clients understand the documents. Friedemann Nauck and co-authors interviewed 53 people who had recently completed advance directives and compared what the people said they wanted with what was recorded in the directive. ${ }^{39}$ They found that advance directive templates often used vague phrases (for example, "to die with dignity") and were rarely tailored to reflect the circumstances of the individual making the directive. ${ }^{40}$ A qualitative study of doctors' experiences of using advance directive templates found that doctors viewed the form as a tool to start a conversation, with some "explicitly claim[ing] that it is not the form, but the conversation itself that matters to them." ${ }^{, 41}$ It appears that lawyers, trained to draft legal documents, place emphasis on the completion of documents and then, to some degree, encourage their clients to have conversations with their loved ones.

Just under half of our respondents reported that they feel they lack adequate information about the medical aspects of ACP. In turn, their clients may be ill-informed as well, especially if they do not discuss their directive with a doctor. Nauck and co-authors found that many people who had made an advance directive "had a poor knowledge of particular clinical situations and the relevance of potential measures." ${ }^{, 42}$ Natalya Thorevska and coauthors reported similar results:

\footnotetext{
This study suggests that patients with living wills did not understand the life-sustaining therapies mentioned in their advance directives. Their preferences for CPR and mechanical ventilation changed when they were provided with American Thoracic Society-approved information. This study confirms that patients with living wills did not fully understand them and had end-of-life wishes that were not reflected fully in their documents. Patients drafted their living wills with the assistance of lawyers and family members, but physicians were generally left out of the process. This is 1 potential explanation for poor understanding of the medical issues (i.e. understanding of terminal illness, end-of-life scenarios, and life-sustaining therapies) in which advance directives are applicable. ${ }^{43}$
}

Lawyers in our survey reported that diagnosis with a life-limiting illness or declining health were common reasons for clients wanting to engage in ACP and it is worth investigating whether their specific illness is addressed in their directive. Nauck and coAnalysis of Their Frequency, Type, and Impact" (2011) 14:4 J Palliative Medicine 483 at 487.

39 Friedemann Nauck et al, "To What Extent Are the Wishes of a Signatory Reflected in Their Advance Directive: A Qualitative Analysis” (2014) 15:52 BMC Medical Ethics, online: <www.biomedcentral. com/1472-6939/15/52>.

$40 \quad$ Ibid at 7

41 Ina Carola Otte et al,"The Utility of Standardized Advance Directives: The General Practitioners' Perspective" (2016) 19:2 Medicine, Health Care \& Philosophy 199 at 203.

$42 \quad$ Nauck et al, supra note 39 at 8.

43 See Thorevska et al, supra note 12 at 30 [footnotes omitted]. 
authors found that people with chronic or terminal illness did not mention "their existing disease in their AD" nor did they go "beyond considering commonly feared scenarios such as artificial nutrition/hydration or being in pain or a coma. Probable end-of-life scenarios relating to their disease were not discussed." 44

Finally, studies should follow up with people who make advance directives and appoint decision-makers to determine the impact of their efforts to plan for what happens to them in the future. As Patricia Biondo and co-authors point out: "Clearly the goal of ACP is not simply to encourage conversations but to ensure that care received is in line with patients' wishes and preferences." 45

\section{CONCLUSION}

The wealth of literature on ACP in health contexts is an important body of knowledge that reveals current practices and investigates strategies that can overcome barriers to improve the uptake of ACP and decision-making that accords with patients' wishes. We believe that a similar evidence base needs to be developed for other professionals involved in promoting and assisting clients with ACP. This study of lawyers is an important step in this direction. 


\section{APPENDIX A: \\ DETAILED SURVEY RESUlts ${ }^{46}$}

\section{Factors That Motivate Client Engagement with ACP}

Question: Typically, from your experience, what prompts a client's desire to engage in advance care planning?

\begin{tabular}{|c|c|c|c|c|c|c|}
\hline & Never & Seldom & Sometimes & Often & Always & $\begin{array}{l}\text { Do not } \\
\text { know or } \\
\text { not sure }\end{array}$ \\
\hline $\begin{array}{l}\text { The lawyer brings it up as part } \\
\text { of a discussion about wills, } \\
\text { power of attorney, etc. with the } \\
\text { client }(n=96)\end{array}$ & $0,0.0 \%$ & $1,1.0 \%$ & $7,7.3 \%$ & $44,45.8 \%$ & $43,44.8 \%$ & $1,1.0 \%$ \\
\hline $\begin{array}{l}\text { The client has received a } \\
\text { medical diagnosis with life } \\
\text { limiting implications and/or is } \\
\text { experiencing deteriorating } \\
\text { health }(n=93)\end{array}$ & $5,5.4 \%$ & $18,19.4 \%$ & $53,57.0 \%$ & $15,16.1 \%$ & $1,1.1 \%$ & $1,1.1 \%$ \\
\hline $\begin{array}{l}\text { The client has had a discussion } \\
\text { with physician or other health } \\
\text { care provider }(\mathrm{n}=91)\end{array}$ & $5,5.5 \%$ & $32,35.2 \%$ & $41,45.1 \%$ & $8,8.8 \%$ & $0,0.0 \%$ & $5,5.5 \%$ \\
\hline $\begin{array}{l}\text { The client is required to do } \\
\text { ACP by residential facility (e.g. } \\
\text { nursing home, supportive } \\
\text { living) (n=93) }\end{array}$ & $10,10.8 \%$ & $24,25.8 \%$ & $41,44.1 \%$ & $14,15.1 \%$ & $1,1.1 \%$ & $3,3.2 \%$ \\
\hline $\begin{array}{l}\text { The client has had a discussion } \\
\text { with financial planner, banker, } \\
\text { insurance advisor }(n=94)\end{array}$ & $3,3.2 \%$ & $23,24.5 \%$ & $40,42.6 \%$ & $26,27.7 \%$ & $0,0.0 \%$ & $2,2.1 \%$ \\
\hline $\begin{array}{l}\text { The client has had a discussion } \\
\text { with a spiritual advisor }(n=89)\end{array}$ & $36,40.4 \%$ & $31,34.8 \%$ & $11,12.4 \%$ & $2,2.2 \%$ & $0,0.0 \%$ & $9,10.1 \%$ \\
\hline $\begin{array}{l}\text { The client has had experience as } \\
\text { caregiver or agent to another }\end{array}$ & $3,3.2 \%$ & $11,11.7 \%$ & $56,59.6 \%$ & $22,23.4 \%$ & $1,1.1 \%$ & $1,1.1 \%$ \\
\hline $\begin{array}{l}\text { There has been an illness or } \\
\text { death of someone close to client } \\
(\mathrm{n}=93)\end{array}$ & $1,1.1 \%$ & $10,10.8 \%$ & $55,59.1 \%$ & $27,29.0 \%$ & $0,0.0 \%$ & $0,0.0 \%$ \\
\hline
\end{tabular}

46 Data is reported as $n, \%$, where $\mathrm{n}$ is the raw number of responses, and \% is the percentage of lawyers that made that particular response. 


\section{Topics Lawyers Discuss with Clients}

Question: When you assist clients with planning for future health care, how often do you discuss or provide guidance about?

\begin{tabular}{|c|c|c|c|c|c|c|}
\hline & Never & Seldom & Sometimes & Often & Always & $\begin{array}{l}\text { Do not } \\
\text { know or } \\
\text { not sure }\end{array}$ \\
\hline $\begin{array}{l}\text { Selecting an agent }(\mathrm{n}=88) \\
\text { [Note: an agent is a person } \\
\text { appointed to make health and } \\
\text { personal decisions] }\end{array}$ & $0,0.0 \%$ & $0,0.0 \%$ & $6,6.8 \%$ & $17,19.3 \%$ & $65,73.9 \%$ & $0,0.0 \%$ \\
\hline $\begin{array}{l}\text { Their values and wishes } \\
\text { concerning future care (e.g., } \\
\text { religious or lifestyle beliefs } \\
\text { important to the client that } \\
\text { they want others to } \\
\text { acknowledge and respect) } \\
(\mathrm{n}=93)\end{array}$ & $0,0.0 \%$ & $1,1.1 \%$ & $11,11.8 \%$ & $29,31.2 \%$ & $51,54.8 \%$ & $1,1.1 \%$ \\
\hline $\begin{array}{l}\text { Their wishes about whether } \\
\text { they would accept or refuse } \\
\text { particular health care } \\
\text { interventions (e.g., } \\
\text { cardiopulmonary } \\
\text { resuscitation, mechanical } \\
\text { ventilation, tube feeding, } \\
\text { kidney dialysis) }(\mathrm{n}=93)\end{array}$ & $2,2.2 \%$ & $9,9.7 \%$ & $11,11.8 \%$ & $21,22.6 \%$ & $49,52.7 \%$ & $1,1.1 \%$ \\
\hline $\begin{array}{l}\text { Their wishes about future } \\
\text { accommodation/living } \\
\text { arrangements }(\mathrm{n}=93)\end{array}$ & $3,3.2 \%$ & $15,16.1 \%$ & $19,20.4 \%$ & $24,25.8 \%$ & $32,34.4 \%$ & $0,0.0 \%$ \\
\hline $\begin{array}{l}\text { Their wishes for who should } \\
\text { be involved in consultations } \\
\text { with the client's health care } \\
\text { team }(n=93)\end{array}$ & $2,2.2 \%$ & $7,7.5 \%$ & $7,7.5 \%$ & $23,24.7 \%$ & $54,58.1 \%$ & $0,0.0 \%$ \\
\hline $\begin{array}{l}\text { Their wishes for who should } \\
\text { have access to their health- } \\
\text { related records }(n=92)\end{array}$ & $5,5.4 \%$ & $17,18.5 \%$ & $18,19.6 \%$ & $20,21.7 \%$ & $32,34.8 \%$ & $0,0.0 \%$ \\
\hline $\begin{array}{l}\text { Their wishes about } \\
\text { participation in medical } \\
\text { research }(n=93)\end{array}$ & $15,16.1 \%$ & $19,20.4 \%$ & $19,20.4 \%$ & $14,15.1 \%$ & $26,28.0 \%$ & $0,0.0 \%$ \\
\hline $\begin{array}{l}\text { Their wishes about organ } \\
\text { donation }(n=92)\end{array}$ & $7,7.6 \%$ & $14,15.2 \%$ & $16,17.4 \%$ & $16,17.4 \%$ & $39,42.4 \%$ & $0,0.0 \%$ \\
\hline
\end{tabular}




\section{Barriers to Assisting Clients With ACP}

\begin{tabular}{|c|c|c|c|c|c|c|}
\hline & Never & Seldom & Sometimes & Often & Always & $\begin{array}{l}\text { Do not } \\
\text { know or } \\
\text { not sure }\end{array}$ \\
\hline $\begin{array}{l}\text { Concerns about upsetting the } \\
\text { client }\end{array}$ & $45,50.6 \%$ & $28,31.5 \%$ & $12,13.5 \%$ & $4,4.5 \%$ & $0,0.0 \%$ & $0,0.0 \%$ \\
\hline $\begin{array}{l}\text { Conversations are upsetting or } \\
\text { uncomfortable for me }\end{array}$ & $63,70.8 \%$ & $21,23.6 \%$ & $4,4.5 \%$ & $0,0.0 \%$ & $0,0.0 \%$ & $1,1.1 \%$ \\
\hline $\begin{array}{l}\text { Client is unwilling to share } \\
\text { personal details with me }\end{array}$ & $15,16.9 \%$ & $34,38.2 \%$ & $31,34.8 \%$ & $8,9.0 \%$ & $0,0.0 \%$ & $1,1.1 \%$ \\
\hline $\begin{array}{l}\text { Differences between the client } \\
\text { and me in age, cultural, religious } \\
\text { or other personal characteristics }\end{array}$ & $43,48.3 \%$ & $34,38.2 \%$ & $10,11.2 \%$ & $1,1.1 \%$ & $0,0.0 \%$ & $1,1.1 \%$ \\
\hline $\begin{array}{l}\text { Lack of client preparedness for } \\
\text { advance care planning }\end{array}$ & $13,14.6 \%$ & $10,11.2 \%$ & $45,50.6 \%$ & $20,22.5 \%$ & $0,0.0 \%$ & $1,1.1 \%$ \\
\hline $\begin{array}{l}\text { My lack of knowledge about } \\
\text { medical aspects of advance care } \\
\text { planning (e.g., lack of knowledge } \\
\text { about medical interventions and } \\
\text { their implications for a client) }\end{array}$ & $25,28.1 \%$ & $21,23.6 \%$ & $25,28.1 \%$ & $9,10.1 \%$ & $6,6.7 \%$ & $3,3.4 \%$ \\
\hline $\begin{array}{l}\text { My lack of knowledge about } \\
\text { health sector policies/practices } \\
(n=88)\end{array}$ & $25,28.4 \%$ & $16,18.2 \%$ & $27,30.7 \%$ & $13,14.8 \%$ & $3,3.4 \%$ & $4,4.5 \%$ \\
\hline $\begin{array}{l}\text { It is time-consuming (and } \\
\text { therefore costly) to have advance } \\
\text { care planning conversations with } \\
\text { clients }\end{array}$ & $43,48.3 \%$ & $29,32.6 \%$ & $10,11.2 \%$ & $6,6.7 \%$ & $1,1.1 \%$ & $0,0.0 \%$ \\
\hline $\begin{array}{l}\text { Concerns that an advance care } \\
\text { plan will not be used in practice }\end{array}$ & $49,55.1 \%$ & $19,21.3 \%$ & $14,15.7 \%$ & $2,2.2 \%$ & $1,1.1 \%$ & $4,4.5 \%$ \\
\hline $\begin{array}{l}\text { My lack of experience with law in } \\
\text { this area }\end{array}$ & $62,69.7 \%$ & $17,19.1 \%$ & $8,9.0 \%$ & $2,2.2 \%$ & $0,0.0 \%$ & $0,0.0 \%$ \\
\hline
\end{tabular}


[this page is intentionally blank] 